\title{
衝突振動系における周期解の厳密な大域表現* (切り換え時刻のみをパラメータとした陽表示)
}

\author{
今 村 \\ 仁*1
Global Representation of Periodic Solution for Vibro-Impact System (Explicit Form Using Implicit Impact Time Parameters)

\author{
Hitoshi IMAMURA*2
}

*2 Mechanical Engineering, Ibaraki University, 4-12-1 Nakanarusawa-cho, Hitachi-shi, Ibaraki, 316-8511 Japan

\begin{abstract}
This paper gives exact and global representation of all periodic solutions appering in 1-DOF vibro-impacting system. The previously derived form of periodic solution by authors can be represented as superposition of periodic solution for linearized system and finite number of continuous periodic functions which is evaluated by equivalent impulsive responses caused by nonlinearity. However, it is not practical, because determination of impact velocities characterising periodic solutions includes infinite product and summation procedures in the form. To avoid this difficulties, relation between two types of representation of periodic solutions, traditional and newly one by authors, is reconsidered. As a result, it is clarified that transcendental equations for periodic connecting conditions in these representations can be mutually transformed by a pair of linear transfomations. According to apply this fact, the finite product and summation scheme determining impact velocities of periodic solutions is derived.
\end{abstract}

Key Words: Nonlinear Vibration, Piecewise Linear System, Vibro-Impact System, Piecewise Connecting Method, Pseudo-Feedback Form, Global Representation, Self Reference, Periodic Solution, Infinite Product Summation Operation

\section{1. 緒言}

状態によって動作モードが切り換わるシステム (PWS システム) は, 多数の部品・要素から構成され るシステムが互いに連動して機能するような系に普遍 的に現れる要素系であり，その動的挙動の解明は，機 械系・電気系を問わず工学のあらゆる分野で重要な研 究課題となっている. 区分線形系は, PWS システム の最も基本的なモデルであり，一般解を区分的な解の 接続により原理的には厳密に構成できるので, 清水ら

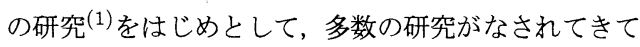
いる. 最近では, 支配方程式の切り替えを微分方程式 に支配された運動に介入する “離散事象”と捉えるこ とにより, アナログとデジタルの両方の性質を併せ持 つハイブリッド・システムとして扱う研究の進展も期 待されている(2). ところが, 動作モードの切り換え時 刻が数值的にしか求められないことや(1), 区分的な厳 密解と解の大域的構造との関係を定量的に評価するこ とが難しいなどの困難が存在し，見掛けの簡単さにも

\footnotetext{
* 原稿受付 2006 年 7 月 28 日.

*1 正員, 茨城大学工学部(严316-8511 日立市中成沢町 4-121).

E-mail : imamura@mx.ibaraki.ac.jp
}

関わらず, この系の動特性は未だ完全な解明には至っ ていない.

著者らは, 上記のような理論的困難の根源は PWS システムに特有の「角 (かど)」や「跳び」のような強 い非線形性に由来する “非解析性” にあると考え, その ような系でも扱える解析手法として，“擬フィードバッ ク形式” と呼ぶ区分線形系の等価モデルを導入した ${ }^{(3)}$. これは，非線形性をそれと等価な外力に置き換えて系 を厳密線形化し，見掛けの重ね合わせの原理を適用し て解く解析体系である，そして，切り換え時閒を直接 求めずにすべて数值的に決定される未知パラメータと して扱っても, 一般解の大域的な構造, 特に周期解や カオスに代表される定常的に切り換えが発生する有界 な解の関数形は大域的に決定できるなど, 従来の方法 では実現できなかった新たな理論解析が可能であるこ とを明らかにしてきた ${ }^{(4) \sim(7)}$. そこで, これまで未知 パラメータとして扱ってきた切り換え時刻を，如何に 効率的に求めるかが次なる重要な研究課題となる。こ れを実現するには，区分的な厳密解の接続では得られ ない大域的な知見の更なる蓄積が不可欠と考えられる. このような観点から，本論文では，周期解の接合法に 


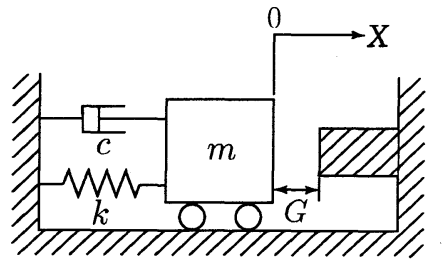

Fig. 1 Physical model of one side impact oscillator

よる接続表現と擬フィードバック形式による重ね合わ せ表現とが如何なる関係で結ばれるかを再考し, 両表 現形式による周期解の成立条件が, ある線形写像で瓦 いに写り合うことを明らかにする.この結果を元に, これまでの著者らの研究では無限の積和演算により形 式的に求めていた周期解上の衝突速度を, 有限回の演 算のみで求める計算法を提案し, あらゆる周期解を陰 的に規定される有限個の衝突時刻のみの関数として表 せる大域的な陽表示式を導出する.

\section{2. 系の記述と問題の設定}

2.1 運動方程式 最も基本的な区分線形システムと して, 図 1 に示す物理モデルで表される系の強制振動 を考察する. 適当なスケール変換により, この系の振 る舞いは, 以下の無次元化された運動方程式で記述で きる(6).

$$
\begin{gathered}
\ddot{x}+2 \zeta \dot{x}+\beta x=\eta \cos (\omega t) ; \quad|x|<\gamma \\
\dot{x}\left(t^{+}\right)=-r \dot{x}\left(t^{-}\right) ; \quad|x|=\gamma
\end{gathered}
$$

$\zeta(\geq 0)$ は粘性減衰係数, $r(0<r<1)$ は質点と衝突境 界 $(x=\gamma)$ との反発係数である. また, $t^{-}, t^{+}$はおの おの衝突直前・直後の時刻である. 以下の議論は, ス トッパーが質量の両側にある系に対しても, 形式的な 修正のみでそのまま成り立つ。

\section{2 接合法 (区分接続形式) による周期解の導出} 系(1) は, 任意の衝突時刻間 $\left(t_{i} \leq t \leq t_{i+1}(i \in \boldsymbol{Z})\right)$ で は線形システムと等価になるので, 線形システムの一 般解を衝突ごとに接続していくことによって，区分的 な襒密解を求めることができる ${ }^{(1)}$. 特に外力の $n$ 周期 間に $m$ 回の衝突を生じる周期解 $\left(\mathscr{X}_{m}^{n}(t)\right.$ と表記する $)$ の場合には, $T \equiv n \cdot 2 \pi / \omega$ を解の周期として, 区分的 な厳密解

$$
\begin{gathered}
\mathscr{X}_{m}^{n}\left(t ; \mathscr{X}_{m}^{n}\left(t_{i}^{+}\right)\right) \equiv \mathscr{T}\left(t-t_{i}\right)\left\{\mathscr{X} \mathscr{X}_{m}^{n}\left(t_{i}^{-}\right)-\mathscr{S}\left(t_{i}\right)\right\} \\
+\mathscr{S}(t) \quad\left(t_{i} \leq t \leq t_{i+1}\right)
\end{gathered}
$$

を衝突時刻ごとに接続したものは, $t=t_{0}+T$ で $t=t_{0}$ での状態に回帰する (図 2 参照). ここで

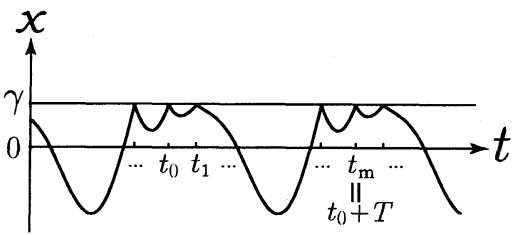

Fig. 2 Example of periodic solution $\mathscr{X}_{n}^{m}(t)$ $(n=1, m=3)$

$\mathscr{X}_{m}^{n}(t) \equiv\left[\mathscr{X}_{m}^{n}(t), \dot{\mathscr{X}}_{m}^{n}(t)\right]^{T}$ は衝突状態ベクトル (た だし, $\left.\mathscr{X}_{m}^{n}\left(t_{i}\right) \equiv \gamma\right),[]^{T}$ を転置行列を表す記号とす る. $\mathscr{T}(t), \mathscr{S}(t)$ はおのおの

$$
\mathscr{T}(t) \equiv\left[\begin{array}{cc}
\mathscr{T}(t) & \mathscr{F}(t) \\
\dot{\mathcal{T}}(t) & \dot{\mathscr{F}}(t)
\end{array}\right], \quad \mathscr{S}(t) \equiv\left[\begin{array}{c}
\mathscr{S}(t) \\
\dot{\mathscr{S}}(t)
\end{array}\right]
$$

で定義される線形システムの状態推移行列と周波数 応答関数からなるべクトルである. $\mathscr{T}(t)$ の各要素は $\beta \neq 0$ では $\beta$ - $\zeta$ パラメータ空間で表 1 のうに, $\mathscr{S}(t)$ は次式により表される.

$\mathscr{S}(t)=\frac{\eta}{\sqrt{\left(\beta-\omega^{2}\right)^{2}+(2 \zeta \omega)^{2}}} \cos \left(\omega t+\tan ^{-1} \frac{-2 \zeta \omega}{\beta-\omega^{2}}\right)$

また, $\mathscr{R}$ は, 衝突直前の状態を衝突直後の状態へ写す 反発行列であり, 次式で定義される.

$$
\mathscr{X}(t) \equiv\left[\begin{array}{cc}
1 & 0 \\
0 & -r
\end{array}\right]
$$

以下では，区分的な厳密解の接続による式(2)のよう な表記法を“区分接続形式” と呼ぶものとする.

しかしながら, 区分的な厳密解は, 隣接する衝突区 間 $\left(t_{i} \leq t \leq t_{i+1}\right)$ では基本的に一般解と同じ構造を有 する形式解であり，周期解の場合には特別に選ばれた 初期条件でのみ, 衝突状態ベクトルを区間ごとの初期 值として，これらが周期的につながる．したがって， 区間ごとには線形システムの過渡成分と定常成分とが 混在したて長な表現となっているので, 周期解を本質 的に構成する定常的な周期関数成分をこの表示式から 見出すことは困難である.

2.3 撒フィードバック形式による周期解の導出 著 者らは, 原系(1)を

$$
\begin{gathered}
\ddot{x}+2 \zeta \dot{x}+\beta x=\eta \cos \omega t-\sum_{t_{i} \in Q}(1+r) \dot{x}\left(t_{i}^{-}\right) \delta\left(t-t_{i}\right) \\
; x \leq \gamma
\end{gathered}
$$

のように厳密線形化し、 ストッパーとの衝突が発生し ない線形システム (“基底線形システム” と呼ぶ) の応 
Table 1 State transfer functions $\mathscr{T}(t)$ and $\mathscr{F}(t)$ for base linear system $\quad \Omega^{ \pm}=\sqrt{ \pm\left(\beta-\zeta^{2}\right)}$

\begin{tabular}{|c|c|c|}
\hline parameters & $\mathscr{T}(t)$ & $\mathscr{F}(t)$ \\
\hline$\beta>\zeta^{2}, \beta \neq 0$ & $\begin{array}{c}e^{-\zeta t}\left(\cos \Omega^{+} t\right. \\
\left.+\frac{\zeta}{\Omega^{+}} \sin \Omega^{+} t\right)\end{array}$ & $e^{-\zeta t} \frac{1}{\Omega^{+}} \sin \Omega^{+} t$ \\
\hline$\beta<\zeta^{2}, \beta \neq 0$ & $\begin{array}{c}e^{-\zeta t}\left(\cosh \Omega^{-} t\right. \\
\left.+\frac{\zeta}{\Omega^{-}} \sinh \Omega^{-} t\right)\end{array}$ & $e^{-\zeta t} \frac{1}{\Omega^{-}} \sinh \Omega^{-} t$ \\
\hline$\beta=\zeta^{2} \neq 0$ & $e^{-\zeta t}(1+\zeta t)$ & $e^{-\zeta t} t$ \\
\hline
\end{tabular}

答と等価外力による応答とを重ね合わせることによっ て大域的な一般解を求める “擬フィードバック形式” に基づく解析法を提案してきた ${ }^{(3)}{ }^{(4)}$. 図 3 は, その 模式図である。ここで, $\delta(t)$ は Dirac のデル夕関数, $Q$ は超越方程式の根である衝突時刻の系列の集合を表 し, その特定の実現值の系列を陰的に規定されるパラ メータとみなす。この方法によれば, 一般解は, 基底 線形システムの一般解と衝突によって発生するインパ ルス応答列 (“前方擬フィードバック過程” と呼ぶ) と の重ね合わせによって大域的に表記できる. 特に周期 解の場合には, 線形システムの定常周期解 $\mathscr{S}(t)$ と衝 突速度 $\dot{\mathscr{X}}_{m}^{n}\left(t_{0}^{-}\right), \ldots, \dot{\mathscr{X}}_{m}^{n}\left(t_{m-1}^{-}\right)$を重みとする $m$ 個の 周期関数との和によって, その関数形を大域的に分解 表示でき, $\beta \neq 0$ の場合には次式となる ${ }^{(6)}$.

$$
\begin{aligned}
& \mathscr{X}_{m}^{n}(t)=\mathscr{S}(t) \\
& \quad+\sum_{i=0}^{m-1} \mathscr{Q}\left(t-t_{i}-T\left\lfloor\frac{t-t_{i}}{T}\right\rfloor\right) \mathscr{V} \mathscr{X}_{m}^{n}\left(t_{i}^{-}\right)(7)
\end{aligned}
$$

ここで $\mathscr{V}$ は次式で定義されるインパルス行列であり，

$$
\boldsymbol{V}=\left[\begin{array}{cc}
0 & 0 \\
0 & -(1+r)
\end{array}\right]
$$

$\mathscr{I}_{2}$ を 2 次の単位行列として

$$
\mathscr{X}=\mathscr{I}_{2}+\mathscr{V}
$$

の関係が成り立つ. $\lfloor x\rfloor$ は $x$ を超えない最大整数, $\mathscr{Q}(t)$ と $p$ はおのおの次式で定義される.

$$
\begin{gathered}
\mathscr{Q}(t) \equiv \frac{\mathscr{T}(t)-e^{-2 \zeta T} \mathscr{T}(t-T)}{p} \\
p \equiv 1-\{\mathscr{T}(T)+\dot{\mathscr{F}}(T)\}+e^{-2 \zeta T} \neq 0(\beta \neq 0)
\end{gathered}
$$

式(7) は数值的にのみ規定される衝突時刻の系列 $t_{0}, \ldots, t_{m-1}$ をパラメータとする形式解である点では 区分的な厳密解の接続による表現(2) と同様であるが, 衝突時刻間に限定されずに大域的に成り立つ周期関数 表現であるという顕著な特長を有する。したがって, 数值的に求められた周期解上の $m$ 個の衝突時刻とそ

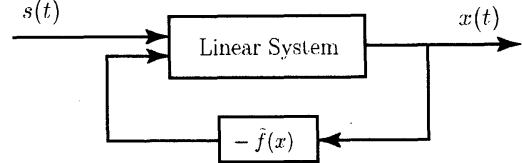

Fig. 3 Schematic diagram of Pseudo-feedback form for piecewise linear system

こでの $m$ 個の衝突速度を式(7)に代入すれば, 周期解 $\mathscr{X}_{m}^{n}(t)$ の関数形が正しく再現できる.

ところが, 式(7) の表現では, 周期解 $\mathscr{X}_{m}^{n}(t)$ は衝突 速度 $\dot{\mathscr{X}}_{m}^{n}\left(t_{i}^{-}\right)(0 \leq i \leq m-1)$ を介して解自身を自己 参照する周期的な循環構造を有する. 速度は変位の時 間微分であるので, 衝突時刻さえ精度良く求められれ ば，衝突瞬間での速度は原理的には計算可能であり， 周期解を規定するために本質的に必要な情報は衝突時 刻だけに半减できるはずである. そこで, この衝突速 度の自己参照を再帰的代入操作により展開・消去寸る と, あらゆる周期解は $m$ 個の衝突時刻 $t_{0}, \ldots, t_{m-1}$ のみで以下のように大域的に表現できる ${ }^{(6)}$.

$$
\begin{gathered}
\mathscr{X}_{m}^{n}(t)=\mathscr{S}(t)+\sum_{k=0}^{m-1} \mathscr{Q}\left(t-t_{k}-T\left\lfloor\frac{t-t_{k}}{T}\right\rfloor\right) \mathscr{V} \\
\times \quad\left[\sum _ { i = 1 } ^ { + \infty } \sum _ { \substack { 0 \leq q _ { 1 } , \ldots , q _ { i - 1 } \leq m - 1 \\
q _ { i } = k } } \prod _ { j = 1 } ^ { i - 1 } \left\{\mathscr { Q } \left(t_{q_{j+1}}-t_{q_{j}}\right.\right.\right. \\
\left.\left.\left.+T u\left(-\left(t_{q_{j+1}}-t_{q_{j}}\right)\right)\right)\right\} \mathscr{V} \mathscr{S}\left(t_{q_{1}}\right)\right]
\end{gathered}
$$

行列の添え字付き積の順序に関しては, 次式のように 左から添え字の減る順に掛けるものとする.

$$
\prod_{i=0}^{m-1} \mathscr{A}_{i}=\mathscr{A}_{m-1} \mathscr{A}_{m-2} \cdots \mathscr{A}_{1} \mathscr{A}_{0}
$$

また, 添え字の空集合に関して, スカラー量の和と積 の值をそれぞれ 0,1 と規約し， $2 \times 2$ 行列 $\mathscr{A}_{i}$ の積に 関しては,

$$
\prod_{\phi} \mathscr{A}_{i}=\mathscr{I}_{2}
$$

と定める.

\section{3. 周期解の接続条件}

式(12) は, 式(7)に現れる $m$ 個の衝突状態ベクトル $\mathscr{X}_{m}^{n}\left(t_{i}\right)$ を無限回の積和演算により求めたものである ので，必ずしも実用的な公式とは言えない．したがっ て, 周期解を本質的に規定できる情報が $m$ 個の衝突時 刻だけであっても，それを大域表現(12)に代入して周 期解の関数形を再現することは難しい，そこで，本論 
文では，区分接続形式と擬フィードバック形式による 解法それぞれによる, 周期解の成立条件の関係につい て考察し，そこから得られた情報をもとに，無限回の 積和演算を経由せずに衝突状態ベクトル $\mathscr{X}_{m}^{n}\left(t_{i}\right)$ を導 出する計算法を提案する. この求められた衝突状態べ クトル $\mathscr{X}_{m}^{n}\left(t_{i}\right)$ を式(7) の右辺に代入すれば, 周期解 を本質的に規定する $m$ 個の衝突時刻のみをパラメー 夕とする，周期解の大域表現が得られたことになる.

3.1 区分接続形式による接続条件 周期解上では, 区分的な厳密解 (2) の衝突時刻での值が衝突状態ベク トルになることから，接合法による周期解の接続条件 に関する以下の連立超越方程式(“接続方程式”と呼ぶ) が得られる。

$$
\mathscr{A}_{m} \mathscr{X}_{m}=\mathscr{B}_{m} \mathscr{S}_{m}
$$

ここで、スペースの節約のため以下の簡略記号

$$
\mathscr{T}_{i, j} \equiv \mathscr{T}\left(t_{i}-t_{j}\right)
$$

を用いるものとし， $\boldsymbol{O}_{2}$ を $2 \times 2$ の零行列とすると, 式(15) は以下のような行列とベクトルの積から構成さ れる.

$$
\mathscr{A}_{m}=\left[\begin{array}{ccccc}
\mathscr{T}_{1,0} \mathscr{R} & -\mathscr{I}_{2} & \mathscr{O}_{2} & \ldots & \mathscr{O}_{2} \\
\mathscr{O}_{2} & \mathscr{T}_{2,1} \mathscr{R} & -\mathscr{I}_{2} & \ldots & \mathscr{O}_{2} \\
\vdots & \vdots & \vdots & \ddots & \vdots \\
\mathscr{O}_{2} & \mathscr{O}_{2} & \mathscr{O}_{2} & \ldots & -\mathscr{I}_{2} \\
-\mathscr{I}_{2} & \mathscr{O}_{2} & \mathscr{O}_{2} & \ldots & \mathscr{T}_{m, m-1} \mathscr{R}
\end{array}\right]
$$

$$
\begin{aligned}
\mathscr{B}_{m} & =\left[\begin{array}{ccccc}
\mathscr{T}_{1,0} & -\mathscr{I}_{2} & \mathscr{O}_{2} & \ldots & \mathscr{O}_{2} \\
\mathscr{O}_{2} & \mathscr{T}_{2,1} & -\mathscr{I}_{2} & \ldots & \mathscr{O}_{2} \\
\vdots & \vdots & \vdots & \ddots & \vdots \\
\mathscr{O}_{2} & \mathscr{O}_{2} & \mathscr{O}_{2} & \ldots & -\mathscr{I}_{2} \\
-\mathscr{I}_{2} & \mathscr{O}_{2} & \mathscr{O}_{2} & \ldots & \mathscr{T}_{m, m-1}
\end{array}\right] \\
\mathscr{X}_{m} & =\left[\begin{array}{llll}
\mathscr{X}_{m}^{n}\left(t_{0}^{-}\right) & \mathscr{X}_{m}^{n}\left(t_{1}^{-}\right) & \ldots & \mathscr{X}_{m}^{n}\left(t_{m-1}^{-}\right)
\end{array}\right]^{T}
\end{aligned}
$$

$$
\mathscr{S}_{m}=\left[\begin{array}{llll}
\mathscr{S}\left(t_{0}\right) & \mathscr{S}\left(t_{1}\right) & \ldots & \mathscr{S}\left(t_{m-1}\right)
\end{array}\right]^{T}
$$

ここで, $\mathscr{X}_{m}$ は周期解 $\mathscr{X}_{m}^{n}(t)$ の $m$ 個の衝突直前の 状態を表す $2 m$ 次のベクトルであり, $\mathscr{S}_{m}$ は, 基底線 形システムの定常周期解の $m$ 個の衝突時刻での状態 を表す $2 m$ 次のべクトルである。また, 本論文では, 行列の行と列の成分に関して, 衝突時刻・衝突速度の 添え字との対比の便宜上, 左上を $(0,0)$ 成分, 右下を $(m-1, m-1)$ 成分とする表記法を用いる.

3.2 据フィードパック形式による接結条件 擬フィー ドバック形式では, 大域的な周期解(7) の $t=t_{i}(0 \leq$ $i \leq m-1)$ での值が衝突状態ベクトルになることか ら, 周期解を構成する連続関数の重ね合わせに関する 条件式として, 以下の連立超越方程式 (“重畳方程式” と呼ぶ) が得られる。

$$
\begin{gathered}
-\sum_{j=0}^{i-1} \mathscr{Q}\left(t_{i}-t_{j}\right) \boldsymbol{V} \boldsymbol{x}_{m}^{n}\left(t_{j}^{-}\right)+\left[\boldsymbol{I}_{\mathbf{2}}-\mathscr{Q}(T) \mathscr{V}\right] \boldsymbol{x}_{m}^{n}\left(t_{i}^{-}\right) \\
-\sum_{i=i+1}^{m-1} \mathscr{Q}\left(t_{i}-t_{j}+T\right) \mathscr{V} \boldsymbol{x}\left(t_{j}^{-}\right)=\mathscr{S}\left(t_{i}\right)(21)
\end{gathered}
$$

$\mathscr{Q}_{\boldsymbol{m}}$ を, 次式を満たす $2 m \times 2 m$ 次行列 $(2 \times 2$ 次行列 を要素とする $m \times m$ 次ブロック行列)

$$
\mathscr{Q}_{\boldsymbol{m}} \equiv\left[\begin{array}{ccc}
\ddots & & -\mathscr{Q}\left(t_{i}-t_{j}+T\right) \mathscr{V} \\
& & (i<j) \\
& \mathscr{I}_{2}-\mathscr{Q}(T) \mathscr{V} & \\
& (i=j) & \\
-\mathscr{Q}\left(t_{i}-t_{j}\right) \boldsymbol{V} &
\end{array}\right]
$$

とすると, 式(21) は以下のような行列形式に書き換え られる。

$$
\mathscr{Q}_{m} \mathscr{X}_{m}=\mathscr{S}_{m}
$$

$\mathscr{Q}_{m}$ は, 超越方程式の根として与えられる衝突時刻に 関して, ある種の対称性と巡回的な構造とを有する正 則行列である.

3.3 区分接続形式と提フィードパック形式との関係 式(15) と式(23) を比較すると, 式(23) は, $\mathscr{S}_{m}$ につい て解いた形式になっているので, これらの左辺に現れ る行列の間には以下の関係が成り立つことがわかる.

$$
\mathscr{A}_{m}=\mathscr{B}_{m} \mathscr{Q}_{m}
$$

$\mathscr{B}_{m}$ は正則であるので, $\mathscr{B}_{m}$ とその逆行列 $\mathscr{B}_{m}{ }^{-1}$ は, 2 種類の周期解の成立条件 (接続方程式と重畳方程式) の間をつなぐ変換になっている. 行列 $\mathscr{B}_{m}$ は, 線形代 数における行基本変形行列 (ただし $2 \times 2$ 行列をその 要素とする) と類似の行列を重ね合わせたような構造 を有するので, その逆行列は, 以下のような行列の積 に分解できる.

$$
\begin{aligned}
\mathscr{B}_{m}{ }^{-1} & =-\prod_{i=0}^{m-2} \mathscr{P}_{i, m-1}\left(\mathscr{T}\left(t_{i}+T-t_{m-1}\right)\right) \\
& \times \mathscr{P}_{m-1}\left(\mathscr{H}(0)^{-1}\right) \prod_{j=0}^{m-2} \mathscr{P}_{j+1, j}\left(\mathscr{T}\left(t_{j+1}-t_{j}\right)\right) \mathscr{D}_{m}
\end{aligned}
$$


$2 \times 2$ 行列を要素とする基本変形行列のうち, $k$ 行を $\mathscr{A}$ 倍したものを $\mathscr{P}_{k}(\mathscr{A}), p$ 行に $q$ 行の $\mathscr{A}$ 倍を加算 したものを $\mathscr{P}_{p, q}(\mathscr{A}), p$ 行と $q$ 行を入れ替えたものを $\mathscr{P}_{p, q}$ とそれぞれ表記する. また, 次式で定義される 行列 $\mathscr{D}_{m}$ を左から掛ける作用は, $i=1, \ldots, m-2$ に 関して, 第 $i$ 行を $i+1$ 行に, $m-1$ 行を 0 行に巡回 させる効果をもつ.

$$
\mathscr{D}_{m} \equiv \prod_{k=0}^{m-2} \mathscr{P}_{k, k+1}=\left[\begin{array}{ccccc}
\mathscr{O}_{2} & \mathscr{O}_{2} & \ldots & \mathscr{O}_{2} & \boldsymbol{I}_{2} \\
\mathscr{I}_{2} & \mathscr{O}_{2} & \ldots & \mathscr{O}_{2} & \mathscr{O}_{2} \\
\mathscr{O}_{2} & \mathscr{I}_{2} & \ldots & \mathscr{O}_{2} & \mathscr{O}_{2} \\
\vdots & \vdots & \ddots & \vdots & \vdots \\
\boldsymbol{O}_{2} & \mathscr{O}_{2} & \ldots & \mathscr{O}_{2} & \mathscr{O}_{2}
\end{array}\right]
$$

また, $\mathscr{H}(0)$ は, 次式で定義される $2 \times 2$ 行列

$$
\mathscr{H}(m)= \begin{cases}\mathscr{I}_{2}-\mathscr{T}(T) & (m=0) \\ \mathscr{I}_{2}-\prod_{k=0}^{m-1}\left\{\mathscr{T}\left(t_{k+1}-t_{k}\right) \mathscr{R}\right\} & (m \geq 1)\end{cases}
$$

の $m=0$ の場合であり, 特に次式が成り立つ.

$$
\mathscr{H}(0)^{-1}=\mathscr{Q}(0)
$$

式(25)の積を計算することにより, $\mathscr{B}_{m}{ }^{-1}$ は次式を満 たす $2 m \times 2 m$ 次行列として与えられる.

$\mathscr{B}_{m}{ }^{-1} \equiv \begin{cases}-\mathscr{Q}\left(t_{i}-t_{j+1}+T\right) & (0 \leq i \leq j \leq m-2) \\ -\mathscr{Q}\left(t_{i}-t_{j+1}\right) & (0 \leq j<i \leq m-2) \\ -\mathscr{Q}\left(t_{i}-t_{0}\right) & (0 \leq i \leq m-1 \\ & j=m-1)\end{cases}$

ここで, 紙数の制約から, 行列 $\mathscr{B}_{\boldsymbol{m}}{ }^{-1}$ の $(i, j)$ 成分を 普通に正方表示せず, 式(29)のように $(i, j)$ 成分の大 小関係に応じた条件式としてコンパクトに表記した. 重鳁方程式(23) を接続方程式(15) 一变換する線形写像 $\mathscr{B}_{m}$ は，大域的に表現された解の情報を局所化する作 用を，一方，接続方程式(15) を重畳方程式(23) 八写す 線形写像 $\mathscr{B}_{m}{ }^{-1}$ は, 区分的な厳密解のもつ情報を大 域化する作用を有すると考えられる.

3.4 程フィードバック形式に基づく逆行列の導出 接続方程式(15), あるいは重畳方程式(23) は, $m$ 個の 衝突時刻を数值的に決定されるパラメータとみなすこ とにより, 衝突状態ベクトル $\mathscr{X}_{m}^{n}\left(t_{i}^{-}\right)(0 \leq i \leq m-1)$ に関する連立一次方程式になっている. したがって， これを解くには, それぞれの係数行列 $\mathscr{A}_{m}$ または $\mathscr{Q}_{m}$
の逆行列を求めなければならない.このうち, 接続方 程式の係数行列 $\mathscr{A}_{m}$ の逆行列の導出については, 3.5 節で検討するので, ここでは重畳方程式(23) の係数行 列 $\mathscr{Q}_{m}$ の逆行列の導出法について検討する. 行列 $\mathscr{Q}_{m}$ は切り換え時刻に関してある種の特徴的な対称性と巡 回構造を持つが, Full Matrix であるので, その逆行 列を Gauss Jordan の消去法などの解法を用いて直接 計算することは難しい，ところが，式(24) から

$$
\mathscr{A}_{m} \mathscr{Q}_{m}^{-1}=\mathscr{B}_{m}
$$

となることより, 行列 $\mathscr{Q}_{m}$ の逆行列は

$$
\mathscr{Q}_{m}{ }^{-1}=\mathscr{A}_{m}{ }^{-1} \mathscr{S}_{m}
$$

のように分解できることがわかる，以下では，式(31) 右辺の積を直接計算するのではなく, $\mathscr{A}_{\boldsymbol{m}}$ と $\mathscr{B}_{\boldsymbol{m}}$ が 式(17), (18)のように対角方向に巡回構造を持つ疎行 列になることに着目して, 式(30)を $\mathscr{Q}_{m}{ }^{-1}$ の要素に 関する連立一次方程式系とみなして解くことにより, 逆行列 $\mathscr{Q}_{m}{ }^{-1}$ を求める.

$\mathscr{Q}_{\boldsymbol{m}}{ }^{-1}$ をとの $(i, j)$ 要素である $2 \times 2$ 行列 $\left(\mathscr{Z}_{i, j}\right.$ と する)を用いて次式のように表記する.

$$
\mathscr{Q}_{\boldsymbol{m}}{ }^{-1}=\left[\begin{array}{cccc}
\mathscr{Z}_{0,0} & \mathscr{Z}_{0,1} & \ldots & \mathscr{Z}_{0, m-1} \\
\mathscr{Z}_{1,0} & \mathscr{Z}_{1,1} & \ldots & \mathscr{Z}_{1, m-1} \\
\vdots & \vdots & \ddots & \vdots \\
\mathscr{Z}_{m-1,0} & \mathscr{Z}_{m-1,1} & \ldots & \mathscr{Z}_{m-1, m-1}
\end{array}\right]
$$

式(30)の両辺に左から $-\mathscr{D}_{m}$ を掛けると

$$
\left[-\mathscr{D}_{m} \mathscr{A}_{m}\right] \mathscr{Q}_{m}{ }^{-1}=-\mathscr{D}_{m} \mathscr{B}_{m}
$$

式(33), (32) より, $\mathscr{Q}_{m}{ }^{-1}$ の各要素は, 以下の連立方 程式を満たす。

$$
\begin{gathered}
\mathscr{Z}_{0, j}-\mathscr{T}_{m, m-1} \mathscr{X}_{m-1, j}=\mathscr{O}_{2} \\
\mathscr{Z}_{1, j}-\mathscr{T}_{1,0} \mathscr{R} \mathscr{Z}_{0, j}=\mathscr{O}_{2} \\
\vdots \\
\mathscr{Z}_{j, j}-\mathscr{T}_{j, j-1} \mathscr{R} \mathscr{X}_{j-1, j}=\mathscr{I}_{2} \\
\mathscr{Z}_{j+1, j}-\mathscr{T}_{j+1, j} \mathscr{R}_{j, j}=-\mathscr{T}_{j+1, j} \\
\vdots \\
\mathscr{Z}_{m-1, j}-\mathscr{T}_{m-1, m-2} \mathscr{X}_{m-2, j}=\mathscr{O}_{2} \\
(0 \leq j \leq m-1)
\end{gathered}
$$

式(34) は，列ごとに独立した連立方程式になっている ので, $\mathscr{Z}_{i, j}(0 \leq i \leq m-1)$ の導出計算は他の列に関 
する超越方程式と干涉することなく実行できる.した がって, 式(27) で定義した $2 \times 2$ 行列 $\mathscr{H}(m)$ の逆行 列 $\mathscr{H}(m)^{-1}$ が求められれば, 式(34) を前進消去によ り $\mathscr{Z}_{0, j}$ について解き, その結果を式(34)に順次後退 代入することにより, $\mathscr{Q}_{\boldsymbol{m}}{ }^{-1}$ の要素である $2 \times 2$ 行列 $\mathscr{Z}_{i, j}(0 \leq i \leq m-1)$ を求めることができる. 以上の 手順により得られた $\mathscr{Q}_{m}{ }^{-1}$ の各成分は次式となる.

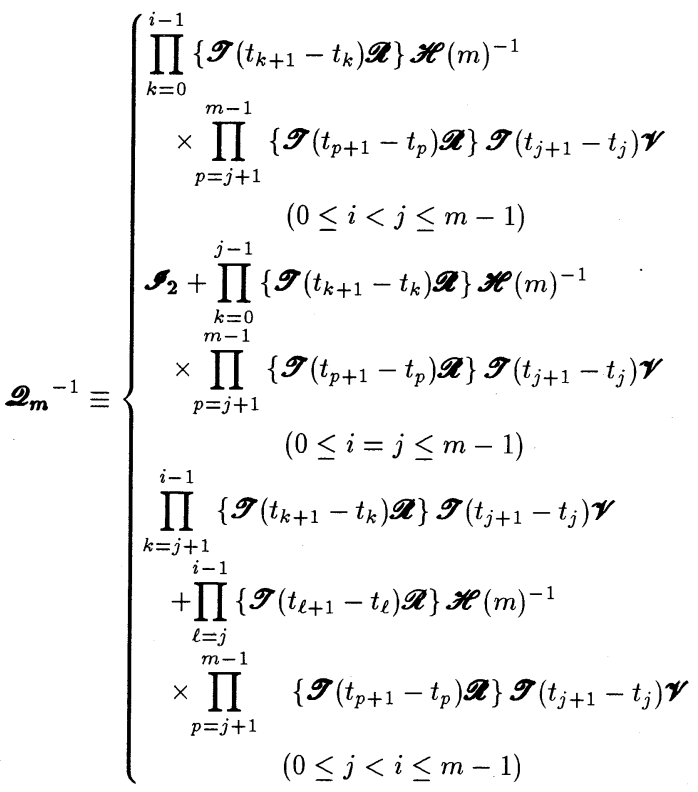

紙数の制約から, 行列 $\mathscr{Q}_{m}{ }^{-1}$ をその $(i, j)$ 成分の満た すべき関係式としてコンパクトに表記した。

式(35) 右辺には, $2 \times 2$ 行列 $\mathscr{H}(m)$ の逆行列が現れ るので, これを求めなければ逆行列 $\mathscr{Q}_{m}{ }^{-1}$ の導出は 完成しない. 正則行列の積の逆行列は, 線形代数学に よれば, 掛けられる各正則行列の逆行列を逆順に掛け たものとなることなどを用いると， $m \geq 1$ に関して， $\mathscr{H}(m)$ の逆行列は次式で与えられる.

$\mathscr{H}(m)^{-1}$

$$
=\frac{\mathscr{I}_{2}-\operatorname{adj}\left(\prod_{k=0}^{m-1}\left\{\mathscr{T}_{k+1, k} \mathscr{R}\right\}\right)}{1-\operatorname{tr}\left(\prod_{k=0}^{m-1}\left\{\mathscr{T}_{k+1, k} \mathscr{R}\right\}\right)+\operatorname{det}\left(\prod_{k=0}^{m-1}\left\{\mathscr{T}_{k+1, k} \mathscr{R}\right\}\right)}
$$

(36)
積に等しいという事実から

$$
\begin{aligned}
\operatorname{det} & \left(\prod_{k=0}^{m-1}\left\{\mathscr{T}_{k+1, k} \mathscr{R}\right\}\right) \\
& =\prod_{k=0}^{m-1} \operatorname{det}\left(\left\{\mathscr{T}_{k+1, k} \mathscr{X}\right\}\right)=\prod_{k=0}^{m-1}\left\{(-r) e^{-2 \zeta\left(t_{k+1}-t_{k}\right)}\right\} \\
& =(-r)^{m} e^{-2 \zeta T}
\end{aligned}
$$

一方, 行列のテンソル積については, そのトレースは 次式のように, 掛けられる各行列のトレースのスカ ラー積に等しい.

$$
\operatorname{tr}\left(\bigotimes_{k=0}^{m-1} \mathscr{A}_{k}\right)=\prod_{k=0}^{m-1} \operatorname{tr}\left(\mathscr{A}_{k}\right)
$$

ところが, 行列の普通の積について，そのトレースを 陽に与える一般的な公式は知られていないようであ る. 式(36) 中に現れる $\operatorname{tr}($ ) $\operatorname{adj}($ ) を計算するため には, 状態推移行列 $\mathscr{T}_{i+1, i}$ のシフトと反発行列 $\mathscr{R}$ の $i, j$ との $m$ 個の積の任意の要素を求める陽公式が必要 となる.

仮に式(36) 中に現れる $\mathscr{X}$ が 2 次の単位行列であれ ば,このような積は状態推移行列の加法定理から容易 に求められる。しかしながら，反発行列 $\mathscr{R}$ を掛けた ものの $m$ 個の積の任意の $(i, j)$ 成分の值の一般形式を 直接計算で見出すことは難しい。そこで, 衝突による 非線形性の効果を“線形システムへの擬フィードバッ クによる重ね合わせ”に置き換えると，そのような陽 表示式は，次式で与えられる.

$$
\begin{aligned}
\prod_{k=0}^{m-1}\left\{\mathscr{T}\left(t_{k+1}-t_{k}\right) \mathscr{R}\right\}=\mathscr{T}\left(t_{m}-t_{0}\right)+\sum_{k=0}^{m-1} \mathscr{T}\left(t_{m}-t_{k}\right) \mathscr{V} \\
\times \sum_{i=2^{k}}\left[\prod_{j=0}^{2^{k+1}-1}\left\{\mathscr{T}\left(t_{d_{j+1}^{(0)}(i)}-t_{d_{j}^{(0)}(i)}\right) \mathscr{V}\right\}\right] \\
\times \mathscr{T}\left(t_{d_{0}^{(0)}(i)}-t_{0}\right)
\end{aligned}
$$

ここで, $\ell_{0}(i)$ は整数 $i$ の 2 進展開表示のビットパター ン中に現れる值 1 の総数であり, 次式で与えられる.

$$
\ell_{0}(i)=\sum_{i=0}^{\left\lfloor\log _{2} i\right\rfloor}\left(\left\lfloor\frac{i}{2^{i}}\right\rfloor \bmod 2\right)-1
$$

$d_{j}^{(0)}(i)\left(0 \leq j \leq \ell_{0}(i)\right)$ は整数 $i$ の 2 進ビットパターン で最下位の桁番号を 0 とし，そこから数えて $j$ 番目に 值 1 が現れる桁番号であり，これらは最上位ビットの 桁番号を与える関数 $d_{\ell(i)}^{(0)}(i)$ を用いて次式のように帰 納的に定義される

$d_{j}^{(0)}(i)=\left\lfloor\log _{2}\left(i-\sum_{k=j+1}^{\ell_{0}(i)} 2^{d_{k}^{(0)}(i)}\right)\right\rfloor \quad\left(0 \leq j \leq \ell_{0}(i)\right)$ 
証明の手順は先に示したもの ${ }^{(5)}$ と同様に数学的帰納法 によるが，表記法が若干異なるので，再録する。

$$
m=1 \text { のときは, }
$$

$$
\begin{aligned}
& \mathscr{T}\left(t_{1}-t_{0}\right) \mathscr{R}=\mathscr{T}\left(t_{1}-t_{0}\right)+\mathscr{T}\left(t_{1}-t_{0}\right) \mathscr{V} \\
& \quad=\mathscr{T}\left(t_{1}-t_{0}\right)+\mathscr{T}\left(t_{1}-t_{0}\right) \mathscr{V} \mathscr{T}\left(t_{0}-t_{0}\right)
\end{aligned}
$$

となり, 式(39) は成り立つ. $m=M$ のとき式(39) が 成り立つと仮定すると, $m=M+1$ では

$$
\begin{aligned}
\prod_{k=0}^{M}\{ & \left.\mathscr{T}\left(t_{k+1}-t_{k}\right) \mathscr{R}\right\} \\
& =\mathscr{T}\left(t_{M+1}-t_{M}\right) \mathscr{R} \prod_{k=0}^{M-1}\left\{\mathscr{T}\left(t_{k+1}-t_{k}\right) \mathscr{R}\right\} \\
& =\mathscr{T}\left(t_{M+1}-t_{M}\right)+\sum_{k=0}^{M-1} \mathscr{T}\left(t_{M+1}-t_{k}\right) \mathscr{V} \\
& \times \sum_{i=2^{k}}^{2^{k+1}-1}\left[\prod_{j=0}^{\ell_{0}(i)-1}\left\{\mathscr{T}\left(t_{d_{j+1}^{(0)}(i)}-t_{d_{j}^{(0)}(i)}\right) \mathscr{V}\right\}\right] \mathscr{T}\left(t_{d_{0}^{(0)}(i)}-t_{0}\right) \\
& +\mathscr{T}\left(t_{M+1}-t_{M}\right) \mathscr{V}\left[\mathscr{T}_{\left(t_{M}-t_{0}\right)+\sum_{k=0}^{M-1} \mathscr{T}\left(t_{M}-t_{k}\right) \mathscr{V}}\right. \\
& \times \sum_{i=2^{k}}\left[\prod_{j=0}^{\ell_{0}(i)-1}\left\{\mathscr{T}\left(t_{d_{j+1}^{(0)}(i)}-t_{d_{j}^{(0)}(i)}\right) \mathscr{V}\right\}\right]
\end{aligned}
$$

式(43) 右辺第 3 項の [ ] 内は

$$
\begin{gathered}
\mathscr{T}\left(t_{d_{0}^{(0)}\left(2^{M}\right)}-t_{0}\right)+\sum_{k=0}^{M-1} \sum_{p=2^{k}}^{2^{k+1}-1} \prod_{j=0}^{\ell_{0}(p)} \\
\cdot\left\{\mathscr{T}\left(t_{d_{j+1}^{(0)}\left(p+2^{M}\right)}-t_{d_{j}^{(0)}\left(p+2^{M}\right)}\right) \boldsymbol{V}\right\} \\
\times \mathscr{T}\left(t_{d_{0}^{(0)}\left(p+2^{M}\right)}-t_{0}\right) \\
=\sum_{i=2^{M}} \prod_{j=0}^{2^{M+1}-1}\left\{\mathscr{T}\left(t_{d_{j+1}^{(0)}(i)}-t_{d_{j}^{(0)}(i)}\right) \mathscr{V}\right\} \\
\times \mathscr{T}\left(t_{d_{0}^{(0)}(i)}-t_{0}\right)
\end{gathered}
$$

のように書き換えられる. 式(44) から(45) への書き換 えで, 添え字パラメータを $i=p+2^{M}$ のように変更 した.これより, 式(43)の右辺は,

$$
\begin{aligned}
\mathscr{T}\left(t_{M+1}-t_{M}\right)+ & \sum_{k=0}^{M} \mathscr{T}\left(t_{M+1}-t_{M}\right) \mathscr{V} \\
\times \sum_{i=2^{k}}^{2^{k+1}-1} & {\left[\prod_{j=0}^{\ell(i)-1}\left\{\mathscr{T}\left(t_{d_{j+1}^{(0)}(i)}-t_{d_{j}^{(0)}(i)}\right) \mathscr{V}\right\}\right] } \\
& \times \mathscr{T}\left(t_{d_{0}^{(0)}(i)}-t_{0}\right)
\end{aligned}
$$

のように書き換えられる. したがって, $m=M+1$ のときも成り立つので, 任意の $m \geq 1$ に対して式(39)
は成り立つ (証明終わり).これらの公式を適用すると, 式(36) 中の $\operatorname{tr}($ ) は, 次式により陽表示できる.

$$
\begin{aligned}
\operatorname{tr}\left(\prod_{k=0}^{m-1}\left\{\mathscr{T}_{k+1, k} \mathscr{R}\right\}\right)=\operatorname{tr}\left(\mathscr{T}_{m, 0}\right) \\
+\sum_{k=0}^{m-1} \sum_{i=2^{k}}^{2^{k+1}-1}\left\{-(1+r) \dot{\mathscr{F}}\left(t_{m}-t_{k}+t_{d_{0}^{(0)}(i)}-t_{0}\right)\right\} \\
\quad \times\left[\prod_{j=0}^{\ell_{0}(i)-1}\left\{-(1+r) \dot{\mathscr{F}}\left(t_{d_{j+1}^{(0)}(i)}-t_{d_{j}^{(0)}(i)}\right)\right\}\right]
\end{aligned}
$$

一方, $\operatorname{adj}()$ は

$$
\begin{aligned}
& \operatorname{adj}\left(\prod_{k=0}^{m-1}\left\{\mathscr{T}\left(t_{k+1}-t_{k}\right) \mathscr{R}\right\}\right) \\
& =\operatorname{adj}\left(\mathscr{T}\left(t_{m}-t_{0}\right)\right)+\sum_{k=0}^{m-1} \operatorname{adj}\left(\mathscr{T}\left(t_{d_{0}^{(0)}(i)}-t_{0}\right)\right) \\
& \times \sum_{i=2^{k}}^{2^{k+1}-1}\left[\prod_{j=0}^{\ell_{0}(i)-1}\left\{\overline{\mathscr{V}} \operatorname{adj}\left(\mathscr{T}\left(t_{d_{j+1}^{(0)}(i)}-t_{d_{j}^{(0)}(i)}\right)\right)\right\}\right] \\
& \times \overline{\boldsymbol{V}} \operatorname{adj}\left(\mathscr{T}\left(t_{m}-t_{k}\right)\right) \\
& =e^{-2 \zeta T}\left[\mathscr{T}(-T)+\sum_{k=0}^{m-12^{k+1}-1} \sum_{i=2^{k}} \mathscr{T}\left(-\left(t_{d_{0}^{(0)}(i)}-t_{0}\right)\right)\right. \\
& \times\left(\prod_{j=0}^{\ell_{0}(i)-1}\left\{\overline{\mathscr{V}} \mathscr{T}\left(-\left(t_{d_{j+1}^{(0)}(i)} t_{d_{j}^{(0)}(i)}\right)\right)\right\}\right) \\
& \left.\times \overline{\mathscr{V}} \mathscr{T}\left(-\left(t_{m}-t_{k}\right)\right)\right]
\end{aligned}
$$

ここで $\overline{\mathscr{V}}$ は

$$
\overline{\mathscr{V}}=\left[\begin{array}{cc}
-(1+r) & 0 \\
0 & 0
\end{array}\right]
$$

であり，

$$
\mathscr{V} \overline{\mathscr{V}}=\overline{\mathscr{V}} \mathscr{V}=\boldsymbol{O}_{2}
$$

を満たす. 式(48) の導出過程で, 切り換え時刻の添え 字指標関数に関して, 次式が成り立つことを用いた。

$$
d_{\ell_{0}(i)}(i)=k \quad\left(2^{k} \leq i \leq 2^{k+1}-1\right)
$$

以上により，逆行列 $\mathscr{H}(m)^{-1}$ の陽表示式が求められ たので, 重畳方程式の係数行列 $\mathscr{Q}_{m}$ の逆行列を直接計 算する公式が導出できた.

3.5 区分接続形式に基づく逆行列の導出 区分接続 形式に基づく超越方程式(15) の係数行列 $\mathscr{A}_{\boldsymbol{m}}$ は式(17) のような疎行列であるが，その逆行列の導出には $2 つ$ の計算法があり得る。一つは, 式(24)を

$$
\mathscr{Q}_{m} \mathscr{A}_{m}^{-1}=\mathscr{B}_{m}{ }^{-1}
$$


のように書き換え, $\mathscr{Q}_{m}{ }^{-1}$ の導出に用いたものと同様 の手順により, 式(52)を $\mathscr{A}_{m}{ }^{-1}$ の要素に関する連立 1 次方程式系とみなして解くことにより求める計算法で ある、今一つは, 式(24)より, $\mathscr{A}_{m}^{-1}$ が

$$
\mathscr{A}_{m}^{-1}=\mathscr{Q}_{m}^{-1} \mathscr{B}_{m}{ }^{-1}
$$

のように分解できることから, 式(53) の右辺に, 式(29), (35) により得られた結果を代入することに よる計算法である. 導出結果は次式となる.

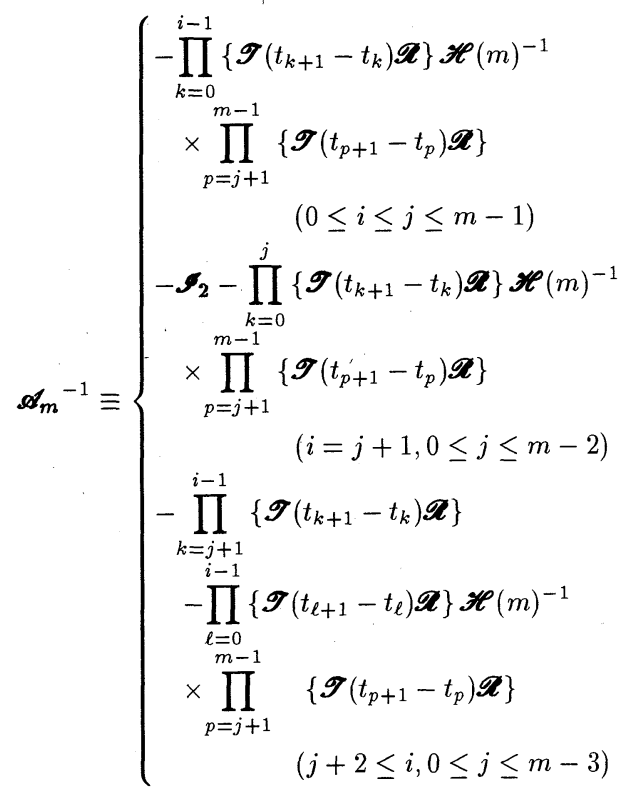

したがって，接続方程式と重疊方程式のどちらをべー スに $\mathscr{X}_{m}$ を求めるとしても, $\mathscr{H}(m)$ の逆行列(36)の 陽表示式が必要となるので, これらの計算の手間は同 程度のオーダーになると考えられる。

\section{6 有限回の積和演算のみによる淺突状態ベクトル}

の導出 以上に示した計算法によって接続方程式あ るいは重盢方程式を解くことにより, 周期解 $\mathscr{X}_{m}^{n}(t)$ 上の $m$ 個の衝突状態ベクトルは次式によって与えら れる。

$$
\begin{aligned}
& \mathscr{X}_{m}^{n}\left(t_{i}^{-}\right)=\sum_{k=0}^{i-1} \prod_{\ell=k+1}^{i-1}\left\{\mathscr{T}\left(t_{\ell+1}-t_{\ell}\right) \mathscr{R}\right\} \mathscr{T}\left(t_{k+1}-t_{k}\right) \mathscr{V} \mathscr{S}\left(t_{k}\right) \\
& +\prod_{\ell=0}^{i-1}\left\{\mathscr{T}\left(t_{\ell+1}-t_{\ell}\right) \mathscr{R}\right\} \mathscr{H}(m)^{-1} \\
& \times \sum_{k=0}^{m-1} \sum_{p=k+1}^{m-1}\left\{\mathscr{T}\left(t_{p+1}-t_{p}\right) \mathscr{R}\right\} \mathscr{T}\left(t_{k+1}-t_{k}\right) \mathscr{V} \mathscr{S}\left(t_{k}\right) \\
& \quad(0 \leq i \leq m-1)
\end{aligned}
$$

これは, 式(12)の右辺に現れる無限の積和演算の評価 結果が, 式(55) で陽に与えられると解釈できる. した がって，周期解の大域表現(7) の右辺に現れる $m$ 個の 衝突状態ベクトルに, 数值的に求められた $m$ 個の衝突 時刻を用いて式(55)により得られた值を代入すれば, あらゆる周期解の関数形が完全に再現できる. 以上に より，無限の積和を経由することなく，有限回の積和 演算のみで，衝突状態ベクトルを導出することが可能 となり，切り換え時刻のみを陰的パラメータとする周 期解の陽な大域表現の構造が明らかになった.

\section{4. 結}

\section{言}

区分的な厳密解の接続による周期解の成立条件の表 現式と, 擬フィードバック形式に基づく見かけの重ね 合わせによるそれとが如何なる関係にあるかを考察 し, これらがある線形写像 (3.1 節の式(18), と $\mathbf{3 . 3}$ 節 の(29)) で互いに写り合うことを明らかにした。この 事実を用いて, 有限個の衝突状態ベクトルを, 無限の 積和表現を経由せずに, 陰的に規定される衝突時刻の 関数として陽に導出した。これらの解析結果を, 陰的 パラメータとして扱った衝突時刻の効率的な数值的計 算法の構築一如何に応用するかの検討については，今 後に残された重要な課題である.

\section{謝 辞}

本研究は, 日本学術振興会科学研究補助金の補助を 受けて行ったものである. 記して謝意を表する.

\section{文献}

(1) Simizu, T., Hisenkei Sindouron, (in Japanese), (1965),114-122, Baifukan.

(2) Imura, J., van der Schaft, A. J., "Well-posedness of a Class of Piecewise Linear Systems with No Jumps", Lecture Note in Computer Science, 1569(1999), SpringerVerlag, 123-136.

(3) Imamura,H., Suzuki, K., "Global Representation of General Solution and Canonical Forms for Piecewise Linear Oscillators: The Case of a Discontinuous Nonlinearity", Trans. Jpn. Soc. Mech. Eng., (in Japanese), 57541,C(1991), 2811-2818.

(4) Imamura,H., Suzuki, K., "Canonical Forms of Periodic Solution for Piecewise Linear Oscillators: Proposition of Feedback Superposition Method", Trans. Jpn. Soc. Mech. Eng., (in Japanese), 64-617, C(1998), 36-44.

(5) Imamura,H., Suzuki, K., "Recursive Feedback Structural Properties Appeared in General Solution for Impact Oscillator Systems", Trans. Jpn. Soc. Mech. Eng., (in Japanese), 66-645, C(2000), 1468-1474.

(6) Imamura,H., Suzuki, K., "General Form of Steady Response and Periodic Solution for Impact Oscillator: The Case Without Sticking", Trans. Jpn. Soc. Mech. Eng., (in Japanese), 67-653,C(2001), 23-29.

(7) Imamura,H., "Exact Derivation of All Periodic Solutions for Impact Oscillator: Proposition of Initial Value Correction Periodize Method", Trans. Jpn. Soc. Mech. Eng., (in Japanese), 70-695,C(2004), 1914-1921. 